\section{Ploidy Level in American Persimmon (Diospyros virginiana) Cultivars}

\author{
Kirk W. Pomper, Jeremiah D. Lowe, Sheri B. Crabtree, \\ and Jacob Vincent \\ Kentucky State University, College of Agriculture, Communities, and the \\ Environment, 205 Cooperative Extension Building, 400 East Main Street, \\ Frankfort, KY 40601
}

Andrew Berry
Bernheim Arboretum and Research Forest, P.O. Box 130, Clermont, KY
40110

Clifford England

England's Orchard and Nursery, 2338 Highway 2004, McKee, KY 404478342

\section{Krit Raemakers}

Plant Cytometry Services, Berkenhof 37, 6941 ZR, Didam, The Netherlands

Additional index words. fruit-set, germplasm, polyploidy, tree-fruit

\begin{abstract}
The American persimmon (Diospyros virginiana) is a slow-growing, moderately sized tree fruit native to the forests of Kentucky. This tree fruit is in the early stages of commercial production with many cultivars selected from the wild. Small orchards of commercially available cultivars are planted in Kentucky. Persimmons are normally dioecious, and female trees require cross-pollination to produce fruit. There are two races of persimmon: the tetraploid (60-chromosome) race is centered in the southern Appalachian region, while the hexaploid (90-chromosome) race generally occupies a range north and west of the tetraploid range. These ranges overlap in Kentucky. Because the ranges overlap, cross-pollination may cause sexual incompatibility, resulting in pollination without fertilization, and therefore seedless fruits of poor quality. The objective of this study was to assess the ploidy level of commercially available American persimmon cultivars and native Kentucky persimmon populations. Leaf samples were collected from 45 cultivars and advanced selections, as well as 45 trees from native populations in Bullitt, Barren, and Franklin Counties. Flow cytometer analysis showed that only four of the selected cultivars were from the tetraploid race: Ennis Seedless, Weeping, Sugar Bear, and SFES; the remaining cultivars were from the hexaploid race. Both hexaploid and tetraploid American persimmon trees were identified in the populations sampled in the Bullitt County locations, but only tetraploid races were found in Franklin and Barren Counties. Because pollen from native trees could result in seedless fruit formation of poor quality when native seedlings are used as pollinizers in commercial production of American persimmon, ploidy level of seedlings needs to be considered.
\end{abstract}

The American persimmon (Diospyros virginiana) is a slow-growing, moderately sized tree-fruit native to the forests of the southeastern and midwestern United States (Nesom, 2018) and is in the early stages of commercial orchard production (Skallerup, 1953). The

Received for publication 6 June 2019. Accepted for publication 16 Oct. 2019.

Published online 16 December 2019.

Kentucky State University Agricultural Experiment Station Publication \# KYSU-000061.

This research was supported by U.S. Department of Agriculture, National Institute of Food and Agriculture, Grant 2010-38821-21522 with Kentucky State University.

K.W.P. is the corresponding author. E-mail: kirk. pomper@kysu.edu.

This is an open access article distributed under the CC BY-NC-ND license (https://creativecommons. org/licenses/by-nc-nd/4.0/).
2005; Goodell, 1982). Ground persimmon seeds have been used as a substitute for coffee (Briand, 2005) and tea made from the leaves of persimmon has antioxidant properties (Kobayashi et al., 2017). Flowers are a significant nectar source for bees (Troop and Hadley, 1895). The most widely cultivated persimmon species across the world is Diospyros kaki, the Oriental or Japanese persimmon, with its large, light yellow-orange to dark red-orange nonastringent fruit; however, this species is not well adapted to the Kentucky climate, and cultivars do not share a similar genetic background (Ames, 2010; Raddová et al., 2012).

American persimmon improvement began in the late 19th century with the work of Dr. James Troop at Purdue University (Plumb, 1896; Troop, 1895; Troop and Hadley, 1895). The first named American persimmon cultivar was selected out of the wild in Illinois in 1880 (Miller, 1894). This original cultivar, Early Golden, has served as the female parent of many of the cultivars developed throughout the 20th century. Professor J.C. McDaniel (1973a) from the University of Illinois had a strong interest in persimmon and was responsible for selecting the cultivars John Rick and Florence. James Claypool continued breeding American persimmon in the 1970s (Goodell, 1982). Over the course of 20 years, Claypool evaluated more than 2000 trees and kept extensive orchard records describing the characteristics of each tree in his breeding project (Jerry Lehman, personal communication). Some of the Claypool selections are commercially available from nurseries.

Troop and Hadley (1895) reported that American persimmons are normally dioecious and require cross-pollination with another cultivar to produce fruit. At least three American persimmon cultivars, Early Golden, Gatterson, and Killen, are usually pistillate (femaleflower) trees; however, some branchlets of staminate (male) flowers occur and can furnish pollen for fruit set (McDaniel, 1973a, 1973b).

There are two races of American persimmon: a tetraploid (60-chromosome) race is centered in the southern Appalachian Mountains and adjacent areas and a hexaploid (90-chromosome) race occupies the range north and west of the tetraploid range (Fig. 1). Using light microscopy observation of root tips stained with crystal violet, hexaploid genotypes were identified for plants generated from seeds collected from trees in Delaware, Georgia, Iowa, Kansas, Louisiana, Mississippi, Missouri, Ohio, Pennsylvania, Texas, Virginia, and West Virginia, whereas tetraploid genotypes were identified from sites in Florida, Georgia, Kentucky, North Carolina, South Carolina, and Tennessee (Baldwin and Culp, 1941). This study included only single tree samples of seeds for most states, although several additional trees were sampled in Georgia, Tennessee, Texas, and Virginia. The ranges for persimmons with these two ploidy levels overlap in Kentucky (Baldwin and Culp, 1941).

Most cultivated American persimmon cultivars are considered likely to be the 


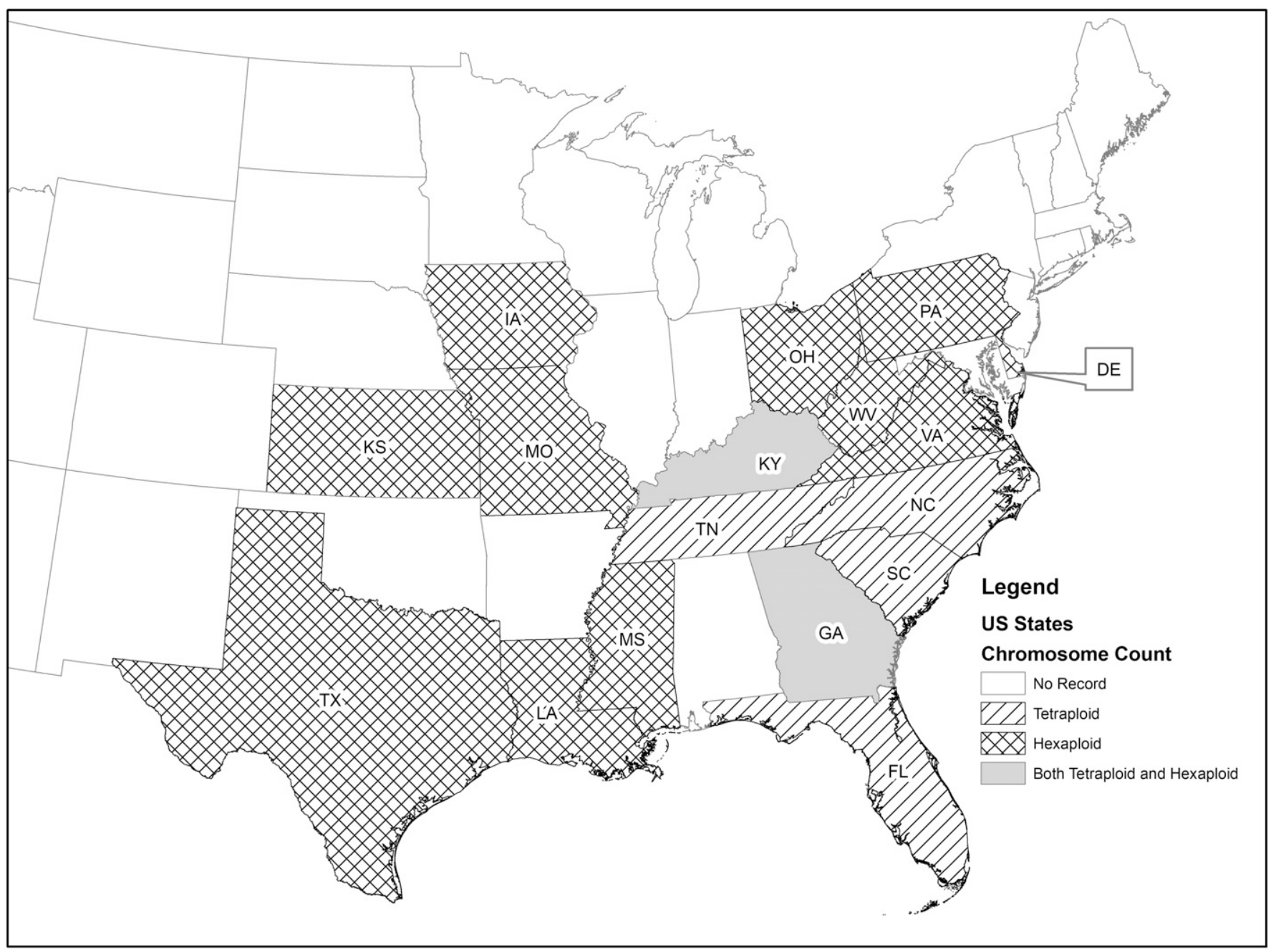

Fig. 1. Reported tetraploid and hexaploid American persimmon populations based on the data of Baldwin and Culp (1941) and data in the current study.

northern hexaploid race; however, there has not been a thorough examination of ploidy level for commercially available cultivars (Choi et al., 2003; McDaniel, 1973a; Nissen and Roberts, 2015). This study is the first to examine the contribution of the tetraploid race toward the commercially available cultivar base. Because both ranges overlap, pollen from a different race with a different pollen ploidy number would result in sexual incompatibility, resulting in pollination without fertilization and the production of seedless fruits. This could allow for the development of orchard production with staminate tetraploid race trees with hexaploid pistillate cultivars to produce seedless fruit. McDaniel (1973a) noted that trees of 'Wabash', a hexaploid, ripen seedless fruit when pollinated by tetraploid males. McDaniel (1973b) noted that seedless fruits of American persimmon do not have as edible a quality because seeded fruits on the same clone and seedless clones are consistently inferior in sweetness to the best seeded cultivars. The objective of this study was to assess the ploidy level of commercially available American persimmon cultivars and native Kentucky persimmon populations to compare tetraploid and hexaploid contributions to this germplasm for grower knowledge.

\section{Materials and Methods}

Plant material. Leaf samples, the youngest three terminal leaves, were collected from 46 cultivars and advanced selections, as well as 45 trees from native populations in Bullitt, Barren, and Franklin Counties. Leaf samples were collected in July 2017 from the American persimmon cultivars Prairie Star, Prairie Sun, Mohler, Early Golden, Garretson, and Meader trees located at the Harold R. Benson Research and Demonstration Farm in Frankfort, Kentucky (Table 1). Leaf samples from additional cultivars or numbered selections were obtained from the budwood mother blocks at England's Orchard and Nursery in McKee, Kentucky. Leaf samples from at least 10 trees at each site were also collected in June and July 2017 from wild American persimmon populations from Bullitt, Barren, and Franklin Counties in Kentucky at sites within one mile of the Global Positioning System coordinates listed in Table 2. Additionally, in October 2018, the average fruit weight and number of seeds per fruit were evaluated for at least 10 fruit from six trees in the area where leaves were previously sampled in Bullitt County, Kentucky (Table 3).

Ploidy level determination. Ploidy analysis was conducted by Plant Cytometry Services (Berkenhof 37, 6941 ZR, Didam, The Netherlands; https://plantcytometry.com/) based on the method of Arumuganathan and Earle (1991). Briefly, leaf material $\left(1-2 \mathrm{~cm}^{2}, 50\right.$ $100 \mathrm{mg}$ ) was chopped with a sharp razor blade in an ice-cold buffer in a plastic petri dish. The DNA buffer consisted of $0.1 \% 4^{\prime}, 6$-diamidino2-phenylindole (DAPI) with $0.1 \%$ dithiothreitol and $1 \%$ polyvinyl pyrrolidone 10 . After chopping, the buffer $(\approx 2 \mathrm{~mL})$, containing cell constituents and large tissue remnants, was passed through a nylon filter $(50-\mu \mathrm{m}$ mesh size). Nuclei were isolated from the leaf samples and stained with the DNA specific dye DAPI. The solution with stained nuclei was sent through a flow cytometer (CyFlow Space; Sysmex Partec GmbH, Görlitz, Germany) with a high-power ultraviolet light-emitting diode (365 nm). Ploidy levels were determined by comparing them with standards Pachysandra terminalis Sieb. \& Zucc. and Vinca minor L. 
Table 1. Ploidy level for American persimmon cultivars.

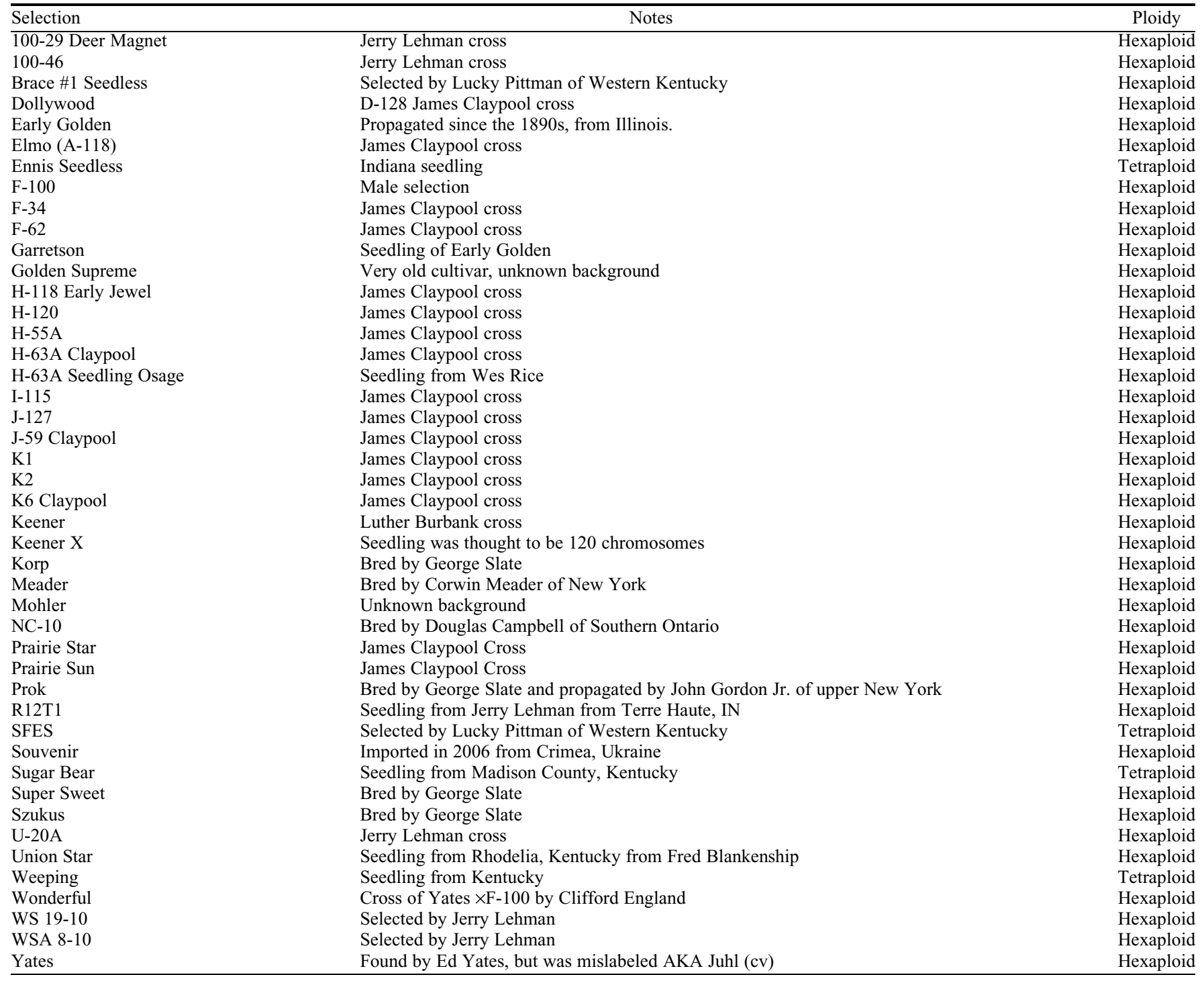

Table 2. Ploidy level in wild American persimmon trees.

\begin{tabular}{lcccc}
\hline County & GPS coordinates & $\begin{array}{c}\text { No. of trees } \\
\text { sampled }\end{array}$ & $\begin{array}{c}\text { No. of tetraploid } \\
\text { trees }\end{array}$ & $\begin{array}{c}\text { No. of hexaploid } \\
\text { trees }\end{array}$ \\
\hline Bullitt & $37.903884,-85.628716$ & 19 & 6 & 13 \\
Barren & $37.101909,-86.058753$ & 21 & 21 & 0 \\
Franklin & $38.175547,-84.915906$ & 5 & 5 & 0 \\
\hline
\end{tabular}

GPS $=$ Global Positioning System.

Table 3. Average fruit weights and seeds per fruit for 10 fruit each from six wild American persimmon trees, sampled in Bullitt County, Kentucky.

\begin{tabular}{lccc}
\hline Tree no. & Avg fruit wt $(\mathrm{g})$ & Avg no. of seeds per fruit & No. of seedless fruit \\
\hline 1 & $11.5 \mathrm{~b}^{\mathrm{z}}$ & $3.0 \mathrm{~cd}$ & 0 \\
2 & $19.3 \mathrm{a}$ & $5.5 \mathrm{a}$ & 0 \\
3 & $8.4 \mathrm{bc}$ & $4.5 \mathrm{abc}$ & 1 \\
4 & $16.3 \mathrm{a}$ & $3.7 \mathrm{~cd}$ & 1 \\
5 & $6.3 \mathrm{c}$ & $1.7 \mathrm{~d}$ & 0 \\
6 & $11.5 \mathrm{~b}$ & $5.0 \mathrm{ab}$ & 0 \\
\hline $\mathrm{z}$ & & &
\end{tabular}

\section{Results and Discussion}

Ploidy levels were determined for 45 American persimmon cultivars commercially available from nurseries. Only four selected cultivars were from the tetraploid race: Ennis Seedless, Weeping, Sugar Bear, and SFES (Table 1). Both hexaploid and tetraploid American persimmon trees were found in the populations sampled in the Bullitt County locations, but only tetraploid races were found in Franklin and Barren Counties (Table 2).

Most cultivated American persimmon cultivars were assumed to be the northern hexaploid race; however, a thorough examination of ploidy level for commercially available cultivars had not been conducted (Choi et al., 2003; McDaniel, 1973a; Nissen and Roberts, 2015). On the basis of the results of this study, it would appear that the hexaploid race has led to the selection of most commercial cultivars although a few cultivars were tetraploid selections. Kentucky is in the unique position to have both races represented in forests around the Commonwealth. There were both hexaploid and tetraploid American persimmon trees in the populations sampled in the Bullitt County locations, whereas only tetraploid races were found in Franklin and Barren Counties. Because the ranges overlap, pollen from a different race may cause sexual incompatibility, resulting in pollination without fertilization and the production of seedless fruits. This could allow for the development of orchard production with male tetraploid race 
trees with hexaploid pistillate cultivars to produce seedless fruit. Many native trees in the forests of Kentucky are of the tetraploid race and grow near commercial plantings of persimmons, and thus pollen from a different race may cause sexual incompatibility and result in pollination without fertilization - and therefore production of seedless fruits of poor quality for consumption. Planting hexaploid female cultivars with male seedling pollinizer trees of the tetraploid race could produce seedless fruit of reduced quality, because some Kentucky forests could have hexaploid native male trees nearby, which could result in seed set of fruit in the commercial hexaploid cultivars. However, in 2018, the number of seeds per fruit was evaluated from at least 10 fruit from six trees in the previously sampled area in Bullitt County Kentucky. Average fruit weight ranged between 6.3 to $19.3 \mathrm{~g}$ on individual trees with a 12.2-g average fruit weight across all trees sampled (Table 3). Average number of seeds per fruit ranged from 1.7 to 5.5 seeds per fruit on individual trees sampled, with an average number of seed per fruit of 3.9 across all trees sampled. Only two fruit of 60 sampled were seedless. Apparently, although pollen from native trees may result in seedless fruit formation in Kentucky and native seedlings, pollen from nearby trees with the same ploidy level is usually sufficient for seed formation in fruit.

Over the course of $20+$ years, James Claypool has evaluated more than 2000 trees and made a number of cultivar releases (Whitson, 2007). Analysis of leaf samples collected from 18 Claypool selections and 10 commercially available showed that all Claypool selections, including Dollywood, Elmo (A-118), F-34, F-62, H-118 Early Jewel, H120, H-55a, H-63a Claypool, H-63a Osage Seedling, I-115, J-127, J-59 Claypool, K1, K2, K6, Prairie Star, and Prairie Sun were all from the hexaploid race; the non-Claypoolselected cultivars Early Golden, Garretson, Golden Supreme, Meader, Mohler, NC-10, and Yates were also from this race. Four nonClaypool-selected commercial cultivars were from the tetraploid race: Ennis Seedless,
Weeping, SFES, and Sugar Bear. These data support the idea that the hexaploid race is also strongly represented in the high-quality material of the Claypool germplasm that was selected (Goodell, 1982). It remains to be seen whether high-quality tetraploid germplasm can be located to contribute toward American persimmon improvement.

In conclusion, this was the first comprehensive study to assess the ploidy level of commercially available American persimmon cultivars and native Kentucky persimmon populations. Flow cytometer analysis of the leaf samples showed that only four selected cultivars were from the tetraploid race: Ennis Seedless, Weeping, Sugar Bear, and SFES. These results support the concept that most cultivated American persimmon cultivars have been selected from the northern hexaploid race. Both hexaploid and tetraploid American persimmon trees were found in the populations sampled in the Bullitt County locations, but only tetraploid races were found in Franklin and Barren Counties. Because pollen from native trees could result in seedless fruit formation in Kentucky, native seedlings could serve as pollinizers in commercial production of American persimmon and have seedless fruit of reduced quality.

\section{Literature Cited}

Ames, G. 2010. Persimmons, Asian and American. ATTRA National Center for Appropriate Technology. 16 July 2018. <http://www.attra.ncat.org/ attra-pub/persimmon.html $>$.

Arumuganathan, K. and E.D. Earle. 1991. Estimation of nuclear DNA content of plants by flow cytometry. Plant Molec. Bio. Reporter 9:229233.

Baldwin, J.T. and R. Culp. 1941. Polyploidy in Diospyros virginiana L. Amer. J. Bot. 28:942944.

Briand, C. 2005. The common persimmon (Diospyros virginiana $\mathrm{L}$.): The history of an underutilized fruit tree (16th-19th centuries). Huntia 12:71-89.

Choi, Y., R. Tao, K. Yonemori, and A. Sugiura. 2003. Genomic distribution of three repetitive DNAs in cultivated hexaploid Diospyros spp.
(D. kaki and D. virginiana) and their wild relatives. Genes Genet. Syst. 78:301-308.

Crandall, B.S. and W.L. Baker. 1950. The wilt disease of American persimmon caused by Cephalosporium diospyri. Phytopathology 40:307325.

Goodell, E. 1982. Two promising fruit plants for northern landscapes. Arnoldia. 42:103-133.

Kaiser, C. and M. Ernst. 2017. American Persimmon. University of Kentucky Cooperative Extension Service, Center for Crop Diversification Crop Profile CCD-CP-1. 15 Jan. 2018. $<$ http:// www.uky.edu/ccd/sites/www.uky.edu.ccd/files/ persimmon.pdfs.

Kobayashi, H., G. Antonious, and K. Pomper. 2017. Phenolic content and antioxidant capacity of American persimmon (Diospyros virginiana L.) teas. J. Amer. Pomol. Soc. 71:91-96.

McDaniel, J. 1973a. Persimmon cultivars for northern areas. Fruit Var. J. 27:94-96.

McDaniel, J. 1973b. American persimmon, an emerging horticultural crop. Fruit Var. J. 27:116-119.

Miller, S. 1894. Our native persimmon. Garden Forest. 7:278-279.

Nesom, G. 2018. Common Persimmon Diospyros virginiana Plant Guide Fact Sheet Natural Resources Conservation Services Plant Database. 16 July 2018. $<$ https://plants.usda.gov/plantguide/ pdf/pg_divi5.pdf $>$.

Nissen, R. and R.E. Roberts. 2015. History, origin and classification of persimmon cultivars. $\mathrm{J}$. Amer. Pomol. Soc. 69:31-44.

Plumb, C. 1896. The American persimmon. Garden Forest. 9:442-443.

Raddová, J., H. Ptáćková1, J. Čechová, and I. Ondrášek. 2012. Genetic analysis of the genus Diospyros ssp. using RAPD and i-PBS methods. Acta Univ. Agr. Silvic. Mendel. Brun. 60:205216.

Skallerup, H.R. 1953. The distribution of Diospyros virginiana L. Ann. Mo. Bot. Gard. 40:211-225.

Troop, J. 1895. Cultivating the persimmon. Garden Forest. 8:75-76.

Troop, J. and O. Hadley. 1895. The American persimmon: Its habits and distribution in Indiana, methods of propagation and cultivation, and suggestions concerning its improvement. Trans. Indiana Hort. Soc. 35:116-123.

Whitson, M. 2007. The pleasing persimmon. Kentucky Native Plant Society. The Lady-Slipper $22: 2-4$. 